\title{
Application of elements of the informed choice of modern contraceptives among reproductive aged women in the Khomas region of Namibia
}

\author{
Petrina Nelumbu ${ }^{1}$, Kristofina Amakali ${ }^{* 2}$, Kathë Hofnie- //Hoëbes ${ }^{2}$ \\ ${ }^{1}$ Ministry of Health and Social Services, Directorate of Primary Health Division of Family Health, Windhoek, Namibia \\ ${ }^{2}$ School of Nursing, Faculty of Health Science, University of Namibia, Windhoek, Namibia
}

Received: July 13, 2015

DOI: $10.5430 /$ jnep.v6n2p130

\author{
Accepted: October 8, 2015 \\ Online Published: November 11, 2015
}

URL: http://dx.doi.org/10.5430/jnep.v6n2p130

\begin{abstract}
A gap still exists between the propositions of the policy and guidelines on the application of the elements of informed choice in family planning services and the reality in practice. This paper presents the findings of the study that was conducted to partially assess and describe the application of the elements of informed choice by the nurses in providing modern contraceptives at the health care facilities in Khomas region of Namibia. A quantitative descriptive study design was employed among the study populations of 7,401 women of reproductive age (15-49 years) who use family planning services at the four (4) urban and two (2) rural health care facilities in Khomas region. Systematic random sampling was done for the urban and rural health facilities, while a convenience sampling was employed to select a sample of 184 client participants from the total population using the computer probability of $95 \%$ and the confidence limit of 5\%. The data were collected through exit interviews of the clients and analysed using EPI Info. The findings indicated a glaring lack of the provision of the information which can constitute the basis for an informed choice by the clients. Based on the findings, the study recommended among others the provision of in-service training in family planning and communication skills for nurses, development and dissemination of Information Education and Communication (IEC) materials for the clients and the availability of more family planning methods for the clients.
\end{abstract}

Key Words: Family planning, Informed choice, Clients, Perspective

\section{INTRODUCTION}

The concepts of "accessibility" and "acceptability" in providing modern contraceptives imply that informed choice is an essential part of family planning service. ${ }^{[1]}$ The Cooperating Agency Task Force on Informed Choice and the Global Family Planning Working Group describe informed choice of family planning as the ability of the client to choose a method of family planning based on the appropriate and adequate information provided to the client. ${ }^{[2]}$
Therefore, the literature suggests that clients of modern family planning services should be informed about the five elements of informed choice: the availability of family planning services and options; voluntary decision making by the clients; good client-provider interaction and counselling; access of individual client to information and support of clients for autonomous decision making in the context of social and clients' right. ${ }^{[3-5]}$ Informed choice and voluntary decision making is therefore a fundamental principle of family planning services.

*Correspondence: Kristofina Amakali; Email: kamakali@unam.na; Address: School of Nursing, University of Namibia, Private Bag 13301, Windhoek, 340 Mandume Ndemufayo Avenue, Pioneerspark, Windhoek, Namibia. 
The availability of service options implies that the clients of family planning services should be informed on a range of family planning methods (and not just one or two methods such as the pills and injectable) from which they can choose a method that best suits their reproductive needs, while the services are also provided at the time most convenient to the clients. ${ }^{[5-7]}$

Voluntary decision making process implies that the clients should have knowledge in order to make a well-considered informed choice of family planning option. ${ }^{[2]}$ In order to promote the effective use of modern contraceptives by the clients, nurses as providers of family planning services should explore the clients' knowledge regarding modern contraceptives. ${ }^{[3]}$ It is therefore important that the providers of modern family planning services tailor the information and guidance they offer to meet the individual needs of each client.

A third element of informed choice relates to client-provider interactions including counselling. ${ }^{[8]}$ Quality client-provider relationship is characterized by respect, privacy and confidentiality. Clients are more likely to seek and continue using Family Planning (FP) services if the treatment they receive is respectful and friendly, their privacy is respected during counselling sessions, examinations and procedures and their needs and personal information are kept confidential. ${ }^{[9]}$ Provision of privacy ensures clients' openness and therefore, to disclose the information that are essential for the appropriate choice of family planning. Privacy also extends an inviting gesture to the client for ongoing use of family planning services. ${ }^{[10]}$ On the other hand, a lack of privacy discourages the clients to participate actively in selecting a family planning method.

The fourth element of the informed choice deliberates on the provision of appropriate family planning information to the clients with regard to the different types and purpose of the family planning methods. In a nutshell, the clients should be given information to understand the desired effects of a specific method, the advantages and disadvantages, the correct use of a method including the use of combined methods for protection against sexually transmitted infections. Common side effects of method chosen should also be explained in terms that the clients are able to understand. ${ }^{[1]}$ The information given in counselling supports the exercises of informed choice by the clients. Moreover, the social context as well as the right of clients to make decisions, forms the basis of autonomous decision making.

The last element of the informed choice elaborates on the influence of the social context and the clients' right on an informed choice of contraceptives. This refers to the laws, policies and cultural norms that either affirm or otherwise pro-

Published by Sciedu Press hibit the individuals to exercise her/his right to reproductive health. Therefore, the providers should explore, identify and propose appropriate remedial actions to the cultural norms that challenge the clients from accessing family planning services.

Equally, the providers of family planning services should respect the clients' rights for an informed choice, assure the clients of support in exercising such rights, and display a positive attitude towards specific population groups such as adolescents and the clients who are at high risk of HIV infection or living with HIV/AIDS in accordance the international treaties, conventions that relate to human, sexual and reproductive rights.

Despite the advocacy for the informed choice for family planning, the literature indicates that there are gaps between policy objectives and the realities at the service delivery. Family planning clients are not given the necessary prerequisites to enable them making informed choice of modern contraceptives. ${ }^{[12]}$

However, there is little if at all, evidence-based information on the application of the elements of an informed choice in family planning services delivery at the Namibian health care facilities that provides family planning services. The question remains: How well are the elements of informed choice being applied at family planning delivery sites in the Khomas region of Namibia?

\section{Purpose of the study}

The purpose of this study was to assess and describe the application of the elements of an informed choice in delivering modern contraceptives by the nurses to women of reproductive age in the Khomas region, Namibia. This paper describes the findings on the application by nurses of the elements of informed choice for the clients of family planning services at the health care facilities in Khomas region, Namibia.

\section{METHOD}

\subsection{Study design and methods}

A quantitative, descriptive study design was employed to assess and describe the application of informed choice for modern contraceptive by the nurses for women of reproductive age at the health family planning facilities in Khomas region during 2010. The study population consisted of all women $(7,401)$ of reproductive age $(15-49$ years old), both new and continuing clients, who at the time of the study used modern family planning methods, irrespective of marital status, parity, level of education and religion. 


\subsection{Sampling of health facilities}

Family planning services in the Khomas region are offered at 11 primary health care facilities: 8 in urban and 3 in rural areas. Each facility has its own estimated catchment area population. In order to ensure that all the facilities had an equal chance of participating in the study, a sampling frame was established in terms of which the eight clinics in the urban areas were listed in alphabetical order. A systematic random sampling technique was used to select a sample of 4 health care facilities from the 8 urban clinics which provide family planning services while 2 rural clinics (out of the three) which serve the larger communities were purposefully included in the study. Thus a total of 6 family planning facilities were included in the study: 4 urban and 2 rural.

\subsection{Sampling of clients}

A sample size of 184 clients was calculated from the total population of 7,401 according to the Creative Research Systems (2007-2010), using the computer sample size calculator with a $95 \%$ confidence level, and a confidence limit of $5 \%$ for accuracy. A convenience or accidental sampling method was then used at each facility to select the participants from the accessible clients who visited the facilities at the time of the study until the sample size of 184 was reached.

Table 1 indicates the number of clients per urban and rural facility contributed to the sample of 184 client participants.

Table 1. Samples of client respondents per in urban and rural health care facilities

\begin{tabular}{lll}
\hline \multirow{2}{*}{ Facility name } & \multicolumn{2}{l}{ Number of participants } \\
\cline { 2 - 3 } & Frequencies & Percentages (\%) \\
\hline Urban Clinics & & \\
Donkerhoek Clinic & 24 & 13 \\
Katutura Health Centre & 73 & 39.67 \\
Okuryangava Clinic & 26 & 14.13 \\
Robert Mugabe Clinic & 53 & 28.8 \\
Rural Clinics & & \\
Dordabis Clinic & 4 & 2.17 \\
Groot Aub Clinic & 4 & 2.17 \\
Total & $\mathbf{1 8 4}$ & $\mathbf{1 0 0}$ \\
\hline
\end{tabular}

\subsection{Data collection instruments}

The data collection tool (questionnaire) was developed based on a conceptual framework for Voluntary, Human RightsBased Family Planning as proposed by the literature ${ }^{[13]}$ and covered the element of: availability of service options, voluntary decision making, individuals possessing appropriate information on family planning, client-provider interaction and counselling as well as the support for autonomous decision making as the indicators of the applications of the elements of informed consent for family planning at the service deliv- ery. In addition to the information on the applications of the elements of informed consent, the demographic information of the respondents, the type and geographic location of the health facilities from where the data were collected were documented.

\subsection{Method of the data collection}

The data on the application of the informed choice by the nurse-providers of family services were collected from the clients who received the services at the participating health care facilities at the time of the study. The data were collected in a timeframe of more than 15 days. At least 10 clients were interviewed per day at the facilities with larger samples. Using the questionnaire, exit interviews of the clients who attended family services were completed. The data pertaining to all five elements of an informed choice for family planning were gathered.

\subsection{Validity and reliability}

Construct validity of the study was assured by the data collection tool/questionnaire which had the questions on the elements of the informed choice for family planning. ${ }^{[13]}$ Content validity was assured by the questionnaires that sought answers to the research questions of the study. The questionnaire was validated by the experts on family planning services at the Ministry of Health and Social Services for content and face validity. The reliability was enhanced though pre-testing of the questionnaire, by following the same procedures for data collection from each client and by making sure that all items in the questionnaire are completed by all the participants.

\subsection{Data analysis}

The Statistical Package for Social Science (SPSS) V21 was used for quantitative analysis of application of the elements of informed choices for modern contraceptives as variables. Descriptive statistics were completed carried out. The next sessions describe the findings.

\section{Findings}

In this section, the findings from the exit interviews of the clients are presented, some of which are presented in tables and charts.

\subsection{Demographic information of the participants}

Out of a total sample of 184 clients who participated in the study, $176(95.7 \%)$ were from the urban facilities while 8 $(4.3 \%)$ were from the rural clinics.

\subsection{Classification of clients}

The clients were classified either as being new-who started family planning for the first time or after a long break of six 
months and more, or as a revisit-who is a regular client of family planning at the current facility, or as a revisit-who started a method of family planning at another facility but has switched to a method which was available at the current facility. In that regard, the findings indicates that 44 (24\%) were new clients while the majority 122 (66\%) of the clients were revisit clients who were regular client at the current facility. The smallest proportion of the clients, 18 (10\%), were revisit clients who had started family planning at another facility but had switched to a method available at the current facility. Thus, the majority of client's -140 of $184(76 \%)$-were revisiting clients and only $24 \%$ were new clients.

\subsection{Ages of clients}

The clients were classified into the age groups along the reproductive age (15-49 years) continuum. The findings in- dicated that the majority (32\%) of the participants fall within the age group of 25-29 years old. Next to the majority were those in the age group of 20-24 years old (22\%) and those who were $30-34$ years old $(18 \%)$.

Figure 1 indicates that only a few $(2 \%$ \& 3\%) of the 184 family planning clients had not any formal schooling, 84 (46\%), had attended school up to grade 8-10, while 57 (31\%) had grade $11-12$ and $21(11 \%)$ of the clients had obtained tertiary education.

Furthermore, the findings indicated that, although $88 \%$ of the client respondents stated that they get the methods of their choices, $79 \%$ indicated that they were not informed about the weekdays when family planning service is provided, while $78 \%$ indicated that they were not informed about the time of the day when family planning service is available.

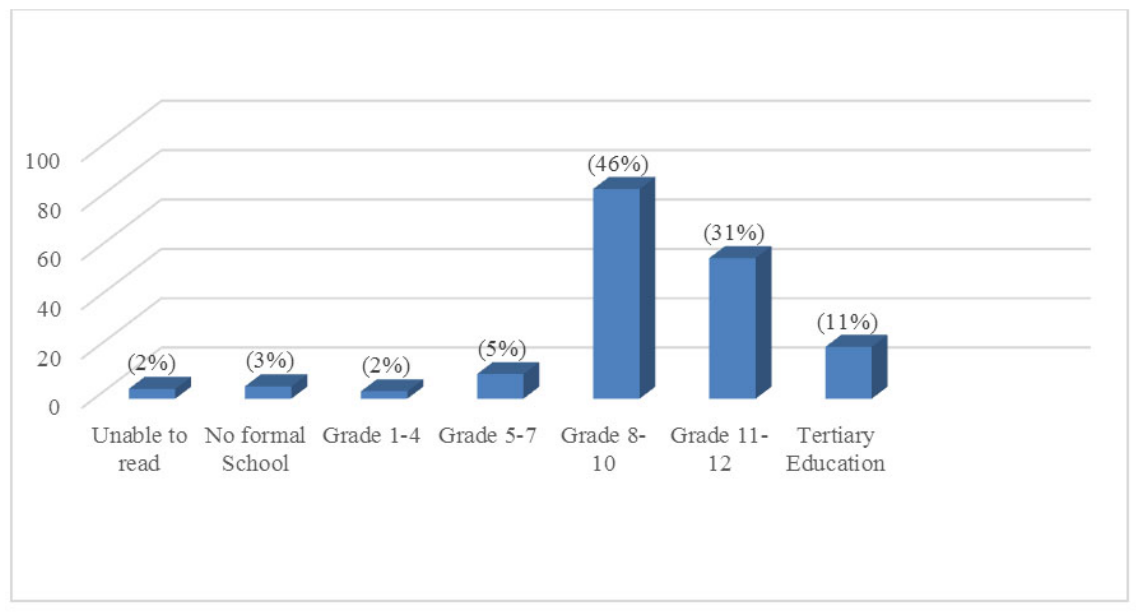

Figure 1. Education levels for family planning clients

Similarly, the findings indicated that the injectable and the pills were the most common methods of family planning that were used by the clients, while condoms were the least used as displayed in Figure 2.

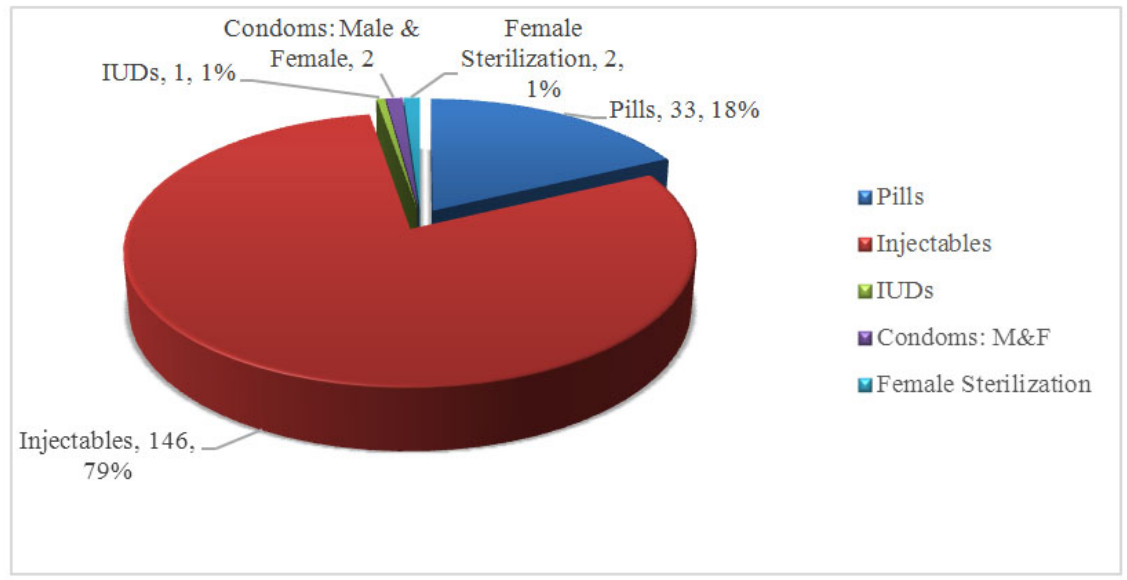

Figure 2. Methods of family planning accessible to clients 


\subsubsection{Voluntary decision making process}

Again, the findings indicate that the majority of the clients were not provided with the information on the chosen family planning method, nor were they given information on other methods of family planning (see Figure 3).

\subsubsection{Client-provider interaction}

The majority (90\%) of the respondents appreciated the respect and non-judgemental attitudes of the nurse-providers towards the clients of family planning. However, the findings indicated that confidentiality is not maintained (73\%), while $38 \%$ of the respondents indicated that the nurse-providers do not answer client's questions.

\subsubsection{Provision of information to clients}

The findings indicated that except the invitation of the clients for follow up that the clients were satisfied with (96\%), the clients indicated that much of the necessary information were not provided to them.

Moreover, the findings indicated that only the minority (34\%) of the clients had the knowledge about the side effects of the injectable contraceptives, a method that is used by $79 \%$ of the respondents.

\subsubsection{Support of clients for autonomous decision making in the context of social and clients' right}

Figure 4 displays the findings regarding the influence of the context and social on an informed choice for family planning.

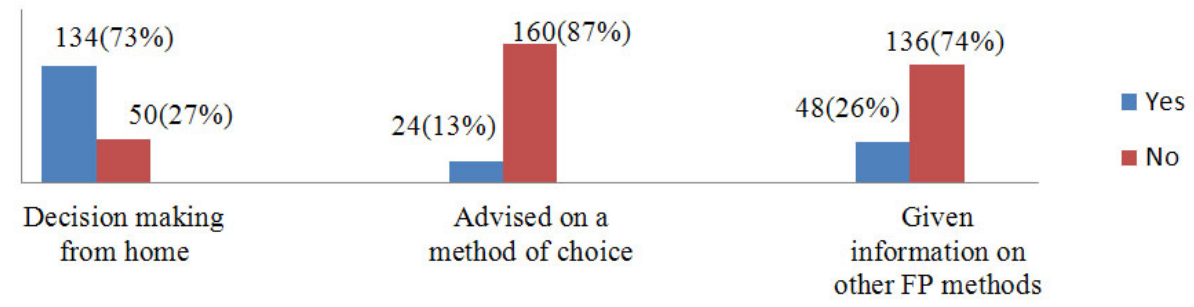

Figure 3. Voluntary decision making by clients

Table 2. Key information pertaining to family planning as reported by the clients $(\mathrm{N}=184)$

\begin{tabular}{|c|c|c|c|c|c|}
\hline \multirow{3}{*}{ Key information pertaining to FP } & \multicolumn{5}{|c|}{ Clients } \\
\hline & \multirow{2}{*}{$\mathbf{N}$} & \multicolumn{2}{|l|}{ Yes } & \multicolumn{2}{|l|}{ No } \\
\hline & & $\mathbf{N}$ & $\%$ & $\mathbf{N}$ & $\%$ \\
\hline Explaining advantages & 184 & 43 & 23 & 141 & 77 \\
\hline Explaining disadvantages & 184 & 73 & 40 & 111 & 60 \\
\hline Explaining STI/HIV & 184 & 95 & 52 & 89 & 48 \\
\hline Explaining how to use method & 184 & 52 & 28 & 132 & 72 \\
\hline Explaining side effects & 184 & 68 & 37 & 116 & 63 \\
\hline Inviting client for follow up visits & 184 & 177 & 96 & 7 & 4 \\
\hline $\begin{array}{l}\text { Asking revisit client whether she is experiencing any problem with the } \\
\text { method she is using }\end{array}$ & 140 & 39 & 28 & 101 & 72 \\
\hline $\begin{array}{l}\text { Asking client who is experiencing problems if she wishes to stop and } \\
\text { switch to another method }\end{array}$ & 39 & 15 & 38 & 24 & 62 \\
\hline
\end{tabular}

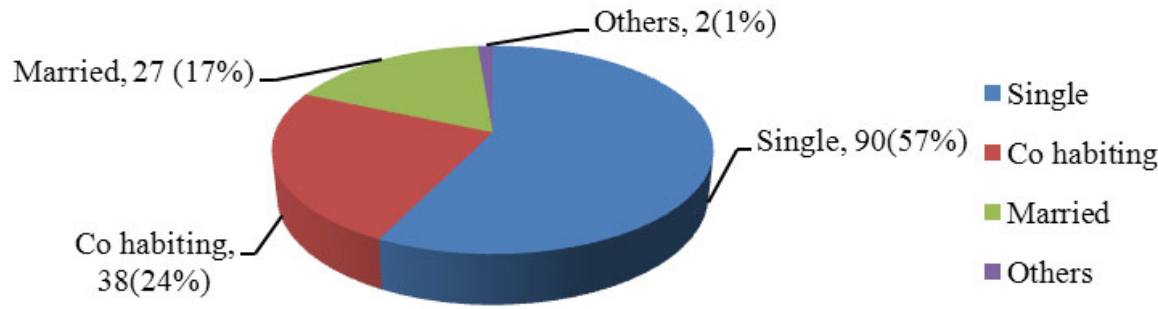

Figure 4. Marital status of the clients 


\section{Discussion}

This section provides a discussion about the application by nurses of the five elements of informed choices for modern contraceptive: the availability of family planning services and options; voluntary decision making process, client provider interaction; access to appropriate information by clients and support of clients for autonomous decision making in the context of social and clients' right.

The findings revealed that the majority of family planning clients use family planning services continuously, have attained a fairly level of education and are therefore able to apply the concept of an informed choice if provided with appropriate information on family planning.

\subsection{Availability of family planning services and options}

As regard this element of the informed choice for family planning services and options, the clients indicated that the most used method of family planning is the injectable contraceptive (79\%), followed by a moderate use of pills (33\%), while the condoms were used minimally by $1.1 \%$ of the participants. These findings concur with the existing literature that the Sub-Saharan Africa countries presented a low use of condoms. ${ }^{[1,14]}$ However, a low use of condoms in the era of the HIV epidemic is a matter of concern and it indicates a lack of comprehensive information by nurses to the clients of family planning on the benefits of different methods of family planning. Thus, the nurses' moderate rating of the availability of all options of family planning to the clients, ${ }^{[15]}$ merely indicates their availability in stock but not that the clients are informed about and use different options of family planning. Therefore, the findings from this study are suggestive that different methods of family planning should be accessible to the clients.

The findings further indicated that the clients of family services were not informed about the schedules for family planning services at the health care facilities. As the literature claims, providers who do not clarify the schedules for the provision of family planning at the health care facility or who refuse to provide the services to clients who seek family planning services at the time other than the scheduled, inversely discourages the clients to make use of family planning services. Therefore, the literature further stresses that the providers of family planning services should provide clients with information about the hours of service and endeavour to provide the services during the hours most convenient to clients. ${ }^{[5]}$

\subsection{Voluntary decision making by the clients}

The second element of informed choice of family planning concerns with voluntary decision making process. Voluntary decision making implies that a client voluntarily makes a well-considered decision based on the knowledge and understanding of the information required either to obtain or decline the service. ${ }^{[16]}$ The findings from this study indicated that the element of voluntary decision making by the clients is not respected by the nurses-providers of family planning services in the Khomas region as demonstrated in Figure 3. Clients were less informed. Hence for the majority, apart from the decisions they have taken at home, when at family planning facilities, the clients were not advised on a specific method, neither given information on different options of family planning. Thus, while the nurses demonstrated a higher rating on the responsibility of health care providers to inform the clients about different options for family planning (94\%) and the clients' right to make the decision on family planning at home $(88 \%),{ }^{[15]}$ the assertions are nonetheless theoretical claims and not the reality in practice.

The literature has proven that the provider's perception may have a negative influence on the client's voluntary choice of contraceptives. This occurs when the service providers believe that they are in a better position to choose the method for the clients or they may be biased in favour of a certain method. Such providers may, in fact, prevent the clients from choosing the methods which are appropriate to their circumstances and reproductive needs. ${ }^{[5]}$

Therefore, the exercises of voluntarily decision making requires a paradigm shift which is client-centred. The clients should, assert their rights, insist on quality services, take responsibility for decision making in choosing a family planning method that meets the individual's reproductive needs and not to rely on the provider to make decisions for them during the family planning counselling. In conclusion, the providers should tailor their guidance with what is the best choice for each client.

The discussion above clarifies the roles of both the client and the provider in decision making to ensure a sound, informed and voluntary choice by the client. This can be realized through a sound client-provider interaction and effective communication $^{[17]}$ as expounded on in the next sessions.

\subsection{Client-provider interaction and counselling}

The third element of informed choice for modern contraceptive is concerned with good client-provider interaction including counselling. The findings from this study indicated that while the majority of the clients claimed that they were treated with respect and listen to by the providers, a moderate number of the client demonstrated dissatisfaction with the nurses' responses to the questions from the clients, while a significant majority of the clients indicated that the providers 
did not ensure or maintain confidentiality. Therefore, the findings from the clients in regard to being listened to by the nurses in the element of voluntary decision making are rather conflicting because a lack of confidentiality and moderate responses to the questions by the nurses does not ensure respect for the clients. It is obvious that lack of privacy during family planning counselling discourages the clients to participate actively in selecting a family planning method, while the assurance of privacy promotes the clients' openness to disclose information that are essential for the appropriate choice of family planning methods. ${ }^{[10]}$

The literature has proven that good interpersonal relationship between the client and the provider is a key element for the client's access to quality family planning services. It is important that the providers respect the clients, and maintain confidentiality towards the clients for the latter to disclose personal information that may be essential for them to make appropriate choices of family planning and at the end, to sustain the use of modern family planning methods. ${ }^{[9]}$

Therefore, during counselling, the providers should apply communication skills and technical knowledge to help the clients toward the appropriate decision and choices of family planning method. Having reached the consensus, the client can then make the decision that meets her family planning needs. Furthermore, in an interaction with the clients, the providers should extend an inviting gesture to the client for the ongoing use of family planning services.

\subsection{Access of individual to appropriate information}

The fourth element of the informed choice relates to clients' access to appropriate information on family planning. This refers to the availability of Information Education and Communication (IEC) materials on family planning, provision and clarification of key information to clients by the nurses and the knowledge of specific family planning methods by the clients. The latter demonstrates quality of information provided to the clients.

The findings from this study showed that only $40 \%$ of the participants indicated that they had seen IEC materials in a health care facility, while a significant $58 \%$ maintained that they had never seen such materials. Lack of access to information materials is substantiated by the clients' claim of lack of explanation on the advantages and disadvantages, side-effects of family planning methods, and a lack of explanation on how to use the method. As a result, the majority $(63 \%)$ of the respondents did not know the side-effects of the injectable contraceptives, a method that was used by the majority $(79 \%)$ of the respondents. Additionally, a shocking $91 \%$ of the clients did not know the remedial action to be taken when a pill is missed (taking the missed pill immediately when remembering and taking the next pill at a regular time). Therefore, these findings conclude that clients of family planning services are not provided with the information to help them make an informed choice of modern family planning methods. Thus, the clients' disclosure regarding this element of an informed choice outweighs the claims by the nurse-providers that the clients are provided with key information for family planning. ${ }^{[15]}$

The materials for the information, education and communication are important in supporting health education and counselling by the nurses to ensure that the clients understand the information given to them by being shown relevant pictures or reading the information for themselves. Information empowers the clients to make a better decision as compared to a client who does not have prior knowledge, thus making the provider's work easier in helping the client to choose the appropriate method of family planning. ${ }^{[4]}$ Therefore, it is appropriate to suggest that even if there are not enough flyers or pamphlets to distribute to the individual clients, posters describing various aspects of modern methods of family planning should be displayed on the walls of the room for family planning services. This enables the client to access the necessary information. It is also important that the information is provided in several sessions to allow clients' learning to take place. ${ }^{[12]}$ In conclusion, emphasis should be placed on the correct and consistent use of each method and the action to be taken in an instance of missed contraceptive, such as a pill, as well as on follow up visits for necessary evaluation and supplies of contraceptives for the sustenance of family planning effort.

\subsection{Support of the clients for autonomous decision mak- ing in the context of social and clients' right}

The last element of an informed choice for family planning is concerned with the social context and the clients' right for an autonomous decision. These are measured by the community's acceptance of the mature women's autonomy to make a decision to use family planning, rather than asking such permission from the partners or obeying the social values that restrict adolescent girls to indulge in sexual activities or to use family planning. As far as the acceptance by the community of the women's autonomy for the decision to use family planning, the findings have proved affirmative. The majority $(85 \%)$ of the respondents indicated that their communities approve of women to make autonomous decision for family planning. Only $10 \%$ of the respondents indicated otherwise, while an insignificant $4 \%$ were neutral. Therefore the findings indicated that the majority of the family planning clients were at liberty of determining their reproductive

ISSN 1925-4040 E-ISSN 1925-4059 
health. This is probably inherent in the communities' awareness and support of gender equality, sexual and reproductive right for the women and the adolescent. Therefore, this is supportive for the use of modern contraceptive by women of reproductive age in Khomas region. However, the findings indicated that unlike single women, married women were at a lesser liberty to autonomously decide whether to use family planning or not, a picture which demonstrates that married women in Namibia are subordinated to their partners regarding the practice of family planning.

Indeed, as the literature proposes, the application of the elements of informed choice for family planning is a foundation to a positive attitude towards family planning service among the clients and the clients would be inspired to continue using the modern methods of family planning. In return, the risks from unplanned and unprotected reproductive activities would be minimized and the clients would improve their socio-economic status. ${ }^{[18]}$

\section{Conclusion}

This article discussed the application of the five elements of the informed choices for modern contraceptives by nurseproviders at the health care facilities in Khomas region of Namibia. The findings were derived from the quantitative, descriptive study, the data of which were collected through an exit interview of family planning clients. The first four elements of the informed choice (the availability of family planning services and options; voluntary decision making process, client provider interaction; access to appropriate information by clients) are in the domain of the implementation by the nurses as the providers of family planning. The last element of the informed choice (support of clients for autonomous decision making in the context of social and clients' right) is rather influenced by the social norms and cultural values of the clients, families and the community and is therefore in the domain of the implementation by the client before seeking family planning services at the health care facilities.

With regard to the elements that are in the domain of the implementation by the nurse-providers of family planning services, the findings indicated poor services to clients by the nurse- providers as demonstrated by less options for family planning which is characterized by a disproportionate high use of the injectable and the pills; poor use of condoms, yet in the era of HIV and the clients who are less informed to make a voluntary decision. Moreover, the findings demonstrated disrespect of clients because the clients' doubt the assurance of confidentiality.

Therefore, the need for the services to improve on the four elements of informed choices which are deliverable by the nurse-service providers cannot be overemphasised.

\subsection{Limitations}

The limitations to the findings are related to the delimitation and methodology of the study respectively. The study was conducted in the Khomas region only and other regions were not included in the study. Thus, the results cannot necessary be generalised to the other regions in Namibia. The information was collected from the clients who were purposely selected, and the selection was influenced by the routine operation at the facilities, where the clients were not registered on entry but they were selected as they were available.

\subsection{Recommendations}

Based on the findings pertaining to all five elements of the informed choices for modern contraceptives, the following recommendations were made among others:

There is a need for the strengthening of orientation of the providers about the national guidelines on family planning at regional and facility levels to enhance the nurses' level of knowledge and skills for them to provide family planning services according to the policy and guidelines. In the same vein, training institution in collaboration with the services providers, should regularly revise the curriculum of the basic nursing training programs on the informed choices for family planning in order to address the knowledge gab among the newly qualified nurses who as nurses would not yet have chance for in-service training on family planning.

Relevant information material such as booklets and flyers on family planning should be developed and be available for the clients to read on their own. Equally, the nurse- providers of family planning services at the public health facilities should provide the clients with all essential information on different options and methods selected to enhance a positive impact on the clients.

Lastly, the study recommends the promotion of condom use as a family planning method for the dual protection against both pregnancy and sexually transmitted infections, especially in the recent era of HIV infection. Strengthening of the provision of health information to the public on the women's right to make autonomous decision about family planning is essential in order to support the women in the context of social and clients' right and therefore to facilitate the successful use of family planning by the clients.

\subsection{Ethical considerations}

The ethical principle of justice, autonomy, respect for a person and beneficence was adhered to in this study. The clients 
of family planning services were justified as the appropriate subjects for the study because they were well-placed to provide the information on the application of the elements of the informed consent by the nurse-providers of family planning services. The purpose of the study and interview procedure was explained to the participants for them to make an informed decision for participation. Voluntarily participation was ensured. ${ }^{[19]}$ Beneficence was ensured by sharing the research findings with relevant authority with the purpose to improve the provision of family planning services in the region, while expectations and potential for distress to the participants were minimized through the clarification of the researcher's role boundary.

\section{ACKNOWLEDGEMENTS}

The division of Family Health in the Directorate of Primary Health Care of the Ministry of Health and Social Services in Namibia is acknowledged for providing the prime researcher with an opportunity to conduct the study among the clients of the health services. Equally, the clients for family planning services who participated in the study are acknowledged for their time and patience to provide valuable information. Without them, the goal of the study would not be realized.

\section{CONFLicts OF InTEREST Disclosure}

The authors declare that there is no conflict of interest.

\section{REFERENCES}

[1] Seiber EE, Bertrand J, Sullivan TM. Changes in contraceptive method mix in developing countries. International Family Planning Perspectives. 2007; 33(3). Available from: http://www.guttmach er.org/pubs/journals/3311707.html PMid:17938094 http: //dx.doi.org/10.1363/3311707

[2] The Respond Project. A fine balance: Contraceptive choice in the 21st century-an action agenda. Report of the September $2012 \mathrm{Bel}-$ lagio Consultation Bellagio, Italy. New York, NY: EngenderHealth; 2012.

[3] Ko IS, You MA, Kim ES, et al. Family planning practice and related factors of married women in Ethiopia. International nursing Review. 2010; 57: 337-382. PMid:20796069 http://dx.doi .org/10.11 $11 / j .1466-7657.2010 .00805 . x$

[4] Gemzell-Danielson K, Thunell L, Lindeberg M, et al. Comprehensive counselling about combined hormonal contraceptives changes the choice of contraceptive methods: Results of the CHOICE program in Sweden. Acta Obstet Gynecol Scand. 2011; 90: 869877. PMid:21564028 http://dx.doi.org/10.1111/j.1600-0 $412.2011 .01180 . \mathrm{x}$

[5] Creel LC, Sass JC, Yinger NV. Client-centred quality: Clients' perspectives and barriers to receiving care. New Perspectives on Quality of Care. No. 2. Washington DC: Population Reference Bureau; 2012.

[6] Cleland JG, Ndugwa RP, Zulu EM. Family planning in Sub-Saharan Africa: progress or stagnation? Bull World Health Organ. 2011; 89: 137-143. PMid:21346925 http://dx.doi .org/10.2471/BLT . 1 0.077925

[7] Ministry of Health and Social Services. National guidelines on family planning. Windhoek, Namibia: MOHSS; 2012.

[8] Kamhawi S, Underwood C, Murad H, et al. Client-centred counselling improves client satisfaction with family planning visits: Evidence from Irbid, Jordan. Global Health Science Practice. 2013; 1(2): 180-192. PMid:25276531 http://dx.doi.org/10.9745/G HSP-D-12-00051

[9] Nanbakhsh H, Salarilak S, Islamloo F, et al. Assessment of women's satisfaction with reproductive health services in Urmia University of Medical Sciences. Health Journal. 2008; 14(3).
[10] Martin A. Active listening skills. The counsellors guide. 2010. Available from: http://www . thecounsellorsguide. comuk/ac tive-listening-skills.html

[11] Centres for Disease Control and Prevention (CDC). Providing quality family planning services: Recommendations of CDC and the US office of population affairs. Atlanta, GA: 2014.

[12] Family Health International. Client-provider interaction: Family planning counselling. Contraceptive Technology and Reproductive Health Series. 2010. Available from: http://www.fhi.360.org/sites/ default/files/webpages/Modules/CPI/s1pg1.htm

[13] Hardee K, Kumar J, Newman K, et al. Voluntary, Human Rights-Based Family Planning: A Conceptual Framework. Studies in Family Planning. 2014; 45 (1): 1-18. PMid:24615572 http: //dx.doi.org/10.1111/j.1728-4465.2014.00373.x

[14] Bankole A, Ahmed FH, Neema S, et al. Knowledge of correct condom use and consistency of use among adolescents in four countries in Sub-Saharan Africa. African Journal of Reproductive Health. 2007; 11(3): 197-220. Available from: http://www.ncbi.nlm .nih.gov/pmc/articles/PMC2367135/ PMid:18458741 http: //dx.doi.org/10.2307/25549740

[15] Nelumbu PN, Hofnie-Hoëbes K. The view of nurses and women of reproductive age regarding the application of informed choice of modern contraceptive in Khomas region. International Journal of Nursing Science. 2015; 2(1): 143-157.

[16] Rajani N, Fabel E. Acquiring knowledge: A focus on fundamentals of care improving family planning and reproductive health care. The Acquire Project. New York, NY: EngenderHealth; 2006.

[17] Family Planning High Impact Practices (HIP). Health communication: Enabling voluntary and informed decision-making. Washington, DC: United States Agency for International Development (USAID); 2012. Available from: http://www.fphighimpactpractices. org/resources/health-communication-enabling-volun tary-and-informed-decision-making

[18] Ollerhead L. What could anthropological studies contribute to improving women's choice for pregnancy planning in SubSaharan Africa? Network for Student Activism. 2011. Available from: http://www.ucl.ac.uk/network-for-student-activ ism/w/What_could_antropological_st

[19] Brink H, Vd Walt C, van Rensburg G. Fundamentals of Research Methodology for Health Care Professionals. Cape Town: Juta; 2013. 